\title{
ALTERNATIIVSEID ETÜMOLOOGIAID IV KORI : KORJA, MELEK(AS), RAHE(-) JA RIKKUMA
}

\author{
LEMBIT VABA
}

Annotatsioon. Artiklis esitatakse uus etümoloogiline tõlgendus sõnadele kori : korja 'lee, kolle', melek(as) 'õõnetuvi', rahe(-): rahejalg, kooljarahe 'surnuraam, puusärgi alus' ja rikkuma 'katki tegema jt'.

Võtmesõnad: etümoloogia, sõnalaenud, eesti keel, läänemeresoome keeled, balti keeled, slaavi keeled

\section{Kori : korja 'koldeauk'}

Eesti kori : korja (ka korjaauk või korisuu) on nüüdseks pea täielikult unustusehõlma vajunud kolde- ehk leeaugu (ka süteauk, tuhkhaud, vt Ränk 1995: 69) nimetus. Õnneks on eesti leksikograafilistes ja etnograafilistes allikates ning mingil määral ka rahvalaulukeeles korja kohta siiski piisavalt materjali, et uurida selle etümoloogilist päritolu. Kori on tähistanud ürgset lahtist tuleaset, kus tehti toitu ja mis eesti rehetoas asus ahjusuu ees; aja jooksul sai see ahju osaks ja moodustas sellega terviku. Pliidi levik tõrjus lahtise tuleaseme XIX saj teisel poolel kõrvale (Tihase 1974: 108-112; ERL 1995: 88) ja selle nimetused kadusid tarvituselt.

Murdesõnaraamatu andmeil on kori : korja 'lee, kolle' kohta teateid Loode-Läänemaalt (Noa LNg Rid Mar) ja Hiiust: Rid ahju suu ees oli kori. ahjust tõmmati sööd korja; suitsutuba oli, 'korjas keedeti; Mar aho korja paes (lõukakivi); Emm Rei korisu(u) 'lee, kolle': Rei Sööd 'veedi korisu; LNg Mar korja- 'lee-, kolde': LNg korja ‘aukos oli tuhk ja tuli; korja paes (paetahvel ahjusuu kohal); Mar korja kibi (lõukakivi) (EMS III,14: 685, 689). Sõna noteerib ka Wiedemann (1973: 346): kori : kor'ja (I, W) 'Vertiefung vor der Ofenmündung', kor'ja-auk, kori-sü id. = kolde-auk. 
Mõisteline sõnaraamat on esitanud sellise selgituse: LoLä kori : korja e. korjaauk, Hi korisuu 'lee [s.o koldeauk, tuhkhaud, augukujuline tulease ahjusuu ees, koldealuse põhjas v. sees olev auk, õõnsus, kuhu söed ja tuhk ahjust tõmmatakse, kus lõke rippuva paja alla süüdatakse], leeauk, koldeauk, tuhkhaud: kui õhtu keedeti, ega siis tuli k[orja]suus ära kustutatud, tuhk aeti sütele peale ja seisis heasti, tuld hoiti k[orja]suus Rei (EKMS I: 67 „Ahi“). Vanemas leksikograafias leidub teade Gösekenilt (1660: 221, 314): „die Grufft für den Riegen Ofen / korri /a, kold /a“. Lisa pakub ka rahvalaulukeel: Siis läks [laisk naine] ahu pääle magama, / Säält kurat kukkus korisu, / Põletas oma käed ja jalad Rei (http://www. folklore.ee/regilaul/andmebaas). Andrus Saareste on koldenimetusi analüüsides kirjutanud, et „lee ehk kolle [on] ahju primaarsem ja olulisem osa ning selle nimetused ka ehk võimalikult vanad" (Saareste 1924: 188). Vanapärane koldeaugu nimetus kori : korja on registreeritud piirkonnast, kus kõige kauem püsisid algelise ehitusega lahtise kerisega ahjud (Ränk 1939: 202-204).

Nikolai Anderson (1879: 210) on üle saja aasta tagasi arvanud, et kori kuulub kokku soome sõnaga korju 'karu (maapealne) talvepesa'. Andersoni kõrvutust on tsiteerinud Saareste (1924: 189) seisukohta võtmata, kõhklemisi on selle esitanud ka SKES II: 219 (vrd) ning SSA 1: 403 (?-ga). Julius Mägiste on kaasanud sõna EEW-sse, kuid pole teinud katset seda etümologiseerida (vt EEW III: 954). Nii häälikulistel kui ka semantilistel kaalutlustel ei ole eesti kori : korja etümoloogiline seostamine läänemeresoome keelte põhjarühma (sm mrd, krj, lü) sõnaga korju jt võimalik. Oletan, et kori : korja on balti laen sõnaperest, mida tänapäeva balti keeltes jätkavad ld kùrti (kùria, kúrè) 'tuld üles tegema, küdema panema, soojaks kütma; rajama, asutama, (kunstiteoseid) looma; tormama, kihutama': kurias ugnis ir be vejo 'põleb tuli tuuletagi', kùras 'küte, kütus, kütteaine'; It kur̃t (kùr kùr, kũra) 'tuld tegema, kütma': uguni kurt 'tuld hakatama', kurêt id., kurs 'küttekolle vanaaegses köögis; ahjutäis küttepuid, küttematerjal; tulease, lee, küttekolle, tuli', kura, kure 'kütmine, tule ülestegemine; ahi', kors '(peam reheahju) suitsukumm sädemete püüdmiseks', ld ùžkura(s) 'ahjutäis puid; leskmees', užkurỹs, It uzkuris 'lesknaisega abiellunud ja tema majja elama asunud mees; naisevanemate kodus elav väimees', sõna-sõnalt '[lesknaise] juurde elama asuja, järelsoojendaja'. Balti sõnaperel on tuletegemist ja tulekollet märkiva semantikaga vasteid ka teistes indoeuroopa keeltes, sh nt vvn курити 'tuld 
üles tegema, süütama', vn mrd кypúmb '(sauna) kütma; (kala) suitsutama; tõrva ajama; suitsema, suitsu ajama', vingl here 'tulease, lee, väike ahi'. Dentaalse laiendiga tüvevariante esindavad nt vingl heorð 'keedukolle, lee, kodu, maja' (vrd eesti kolle 'tule-, küttekolle; kodu'), vüsks herd id. (www.tezaurs.lv; ME 2: 321, 325-326; EH 1: 639; LEW I: 319; Toporov 1984: 300-307; Mažiulis 1993: 306-307; ĖSSJa 13: 123-125 sub *kuriti (sę); Karaliūnas 1997: 259-275; ALEW 1: 543-544).

Kori : korja eeldab balti ia-tüvelist laenualust *kuria- oletatava algtähendusega 'tuli, tulepesa'. Selletüvelisi balti laene esindavad eesti keeles nt hari : harja, ? kari : karja, mrd süri : sürjä 'liivane kõrgustik, liivaluide', takjas : takja, tühi : tühja, vähi : vähja. Hälbiva $o$ ootuspärase $u$ asemel on võinud peale sundida häiriv homonüümia (nt kuri : kurja) vms.

\section{$\operatorname{Melek(as)}$ 'õõnetuvi'}

Melekas on õõnetuvi (Columba oenas) rahvapäraseid nimetusi. Murdesõnaraamatu andmeil on selle (koos häälikuvariantidega) levila järgmine: melek: meleki melekä Kod, melekas : meleka IisR JJn Sim I, meelekas : meeleka Mar Tür KJn, ‘mieleka VNg, meelik : meeliku Hää Juu, meelikas 'ka: mingi väike, punase kõhualusega lind' Muh (EMS V,25: 1011; VI,26: 14). Mart Mägerilt võib veel lisada variandi mälakas Pal Lai (Mäger 1967: 92). Lisateavet pakub ka rahvalaulukeel: Sisask laulab saaninagi, / Halli lindu aisanagi, / Melekas mehe õlana, / Kägu kukub kol'onai MMg; Meelek oli mehe õlana / Sisask saani veere peala / Tema lukud looga peale / Halli lindu haisa pääle Äks (http://www.folklore.ee/regilaul/ andmebaas). Hupeli sõnaraamatus $(1818: 139,434)$ leiduvad häälikkujud melleke ja mellek 'wilde oder Holztaube' Pp.; tõenäoliselt sellest allikast pärineb Wiedemanni (1973: 594) mellekene (Pp.). Hilisema murdeuurimise käigus pole niisugust tüvevarianti registreeritud, selle faktilisus ongi kaheldav: arvatavasti on tegemist vanakirjaviisilise ortogrammi masinliku ülevõtuga uude kirjaviisi. Õõnetuvi on olnud ja on vähesel määral ilmselt tänapäevalgi jahilind, ehkki tema arvukus on drastiliselt vähenenud (http:// www.ejs.ee/wp-content/uploads/2015/02/jahilinnud.pdf). Hoolimata erinevustest välimuses ja ökoloogias ei erista rahvas õõnetuvi kaelustuvist (Columba palumbus). Ka häälitsemine ei tõmba teravat piiri kahe liigi vahele ja nii sulavad nad üheks metstuviks (Lõo 1913: 258-259; Mäger 1967: 89). 
Linnunimetuse melekas päritolu kohta on asjaomases kirjanduses esitatud mitmesuguseid arvamusi. Andrus Saareste (1924: 92) kaldub seda pidama „onomatopoeetseks kujunduseks“, temale apelleerib Mart Mäger (1967: 92), kõhklevalt ka Alo Raun (1982: 91). Mäger rõhutab sealjuures, et enamasti on tuvinimetused onomatopoeetilist algupära (ibid.: 90). Ent õõne- ja kaelustuvi häälitsuste rahvalikud tõlgendused ei näi seda seisukohta meleka puhul toetavat; ka Julius Mägiste on otsustavalt tõrjunud meleka onomatopoeetilist alget (EEW V: 1526-1527). Teise oletuse kohaselt on eesti melekas lms-md ühistüve jätkaja, kus - $l$ - on võinud lähtuda kunagisest algsest afrikaadist: $1 \mathrm{~ms} *_{-t-}:-\delta-<<\mathrm{s}-\mathrm{u} *_{c}$, vrd sm mrd mettinen jt 'turteltuvi', mdE m'eče, m'eča 'tuvi' (Toivonen 1928: 73, 208; Tooms 1933: 10). See oletus on Mägiste arvates aga ülimalt küsitav ja kõne alla võiks pigem tulla kontaminatsoon linnunimetustest mehikas $\sim$ mehekas 'kaelustuvi' ja meltsas 'roherähn; kaelustuvi' (EEW V: 1526-1527).

Meleka päritolu üle juureldes ei saa eirata leedu keele uurija, teoloog Kazimieras Jauniuse 1880.-1890ndate paiku tehtud kõrvutust leedu linnunimetusega meletà (vt Jaunius 1972: 329). Leedu meletà (mrd ka malatà, molatà, metateetiliselt lemetà) tähistab mitut rähniliiki, nagu žalioji meleta 'roherähn (Picus viridis)', juodoji meleta 'musträhn (Dryocopus martius)', samuti mesilasenäppi (Merops apiaster) ja siniraaga (Coracias garrulus) (http://www.lkz.lt) ja võib-olla ka laanepüüd ja metsist või tetre ('Hasel-, Waldhuhn', vt http://woerterbuchnetz.de/cgi-bin/WBNetz/genFOplus. tcl? sigle $=$ DWB\&lemid $=$ GW03854; Walde 1930: 294). Linnunimetuste kõrval iseloomustab ld meletà lobisemishimulist ja mesimagusa jutuga inimest, lõmpslõuga, lipitsejat (Sereiskis 1933: 472; http://www.lkz.lt). Leedu sõna muinaspreisi vaste on melato 'roherähn'; blt *melatā $\sim$ *meletā on etümoloogiliselt seotud baltoslaavi sõnaperega *mel- 'hõõruma, jahvatama; lobisema', kuhu kuuluvad mh málti 'jahvatama; tüütult palju rääkima, latrama' (jì mãla kaĩp malatà 'ta [naisterahvas] jahvatab (lobiseb) nagu roherähn'), mõle 'jahvatamine, jahvatus', lt maĩt 'jahvatama; lobisema, latrama', mèle 'keel (anat)', vvn мелея 'veski', vn mrd мелея' 'käsikivi vänt; veskikivi; tuuleveski; käsikivil jahvataja; lobiseja, lobasuu, lobamokk, jahvard, laterdis, latatara', ме́ля, меле́ха id., ме́лево 'jahvatus, jahvatamine; lora, tühi jutt', vlgvn mrd мэ́лю́x 'lobamokk'. Wojciech Smoczyński järgi on võib-olla võimalik seos sõnaperega, kuhu kuuluvad nt ld mẽlas 'vale', It mẹli mitm 'vale, valetamine', mèlst 'luiskama, lobisema, loba ajama', ld melúoti 'valetama', 1t mȩluôt id. (LEW I: 401; Mažiulis 1996: 122-123; 
Blažek 1998: 14; Smoczyński 2016: 783, 784; ÈSSJa 18: 82-83, 90-91 sub *melěja $\sim$ *melějb, *melexъ, *melivo). Balti *melatā * *meletā on kahtlemisi seotud tumedaid värvitoone märkiva indoeuroopa etümoniga *mel-, *mela (Walde 1930: 294; Pokorny 2: 720-721); seda seisukohta uuem etümoloogiline kirjandus ei kajasta.

Häälikuliselt ei ole balti etümoloogia suhtes tõrkeid. Laenualuse lõpuosa *-tā korvamine $k(a s)$-liitega pole ootamatu, sest liide on üliproduktiivne, esinedes sh arvukates linnunimetustes. Eesti keeles esineb sõnalaene, kus laenualuse lõpuosis $-t(V)$ on korvatud $k(a s)$-liitega: kapuk(as) 'pikema säärega sokk' < vn кonbimo 'kabi, sõrg; mrd kabjakujuline naiste peakate' (vt ka EEW III: 701); lupak(as) 'riideräbal jt' < 1t lupata 'kalts, narts' (Vaba 1997: 125-126), poluk, -u Hel 'magamisase, riiul' < vn пола́mu 'lavats' (Must 2000: 278-279), ra(a)vak, -u Hel 'magamisase' < vn кровámь 'voodi' (ibid.: 135-136), rantsakas, rantsalind Jõh 'merisk (Haematopus L.)'< rts strandskata id. (Mäger 1967: 62), uplikas Lih, suplikas Kuu 'sõtkas' (Mäger 1967: 37) ? < erts alplit, aplikt 'merisk', vrd eesti mrd plit't : pliti plikk : plika id., mis lähtub ühemõtteliselt eeltoodud erts laenualusest (Ariste 1933: 89).

Meelekas, meelik jt on sekundaarsed häälikuarengud; Häädemeeste keelejuht on seletanud, et ,meelik oleva sellepärast, et mahedasti laulab“ (Mäger 1967: 92). Ebaselgeks jääb meleka etümoloogiline suhe peamiselt roherähni, kuid Põhja-Eestis paiguti ka metstuvi tähistavate nimetustega mel'gas : melka, mõlgas : mõlka jt. Mäger $(1967: 92,117)$ oletab kontaminatsiooni meigas $\sim$ mõigas 'kaelustuvi' + meltsas $\sim$ mõltsas $>$ melgas $\sim$ mõlgas ja osutab tähenduste 'metstuvi' ja 'roherähn' ristumisele, mida on soodustanud sõnade kõlaline lähedus. Mägiste arvates on selline seletus usutav (EEW V: 1527).

\section{Rahe(-): rahejalg, kooljarahe 'surnuraam, puusärgi alus' versus (k)raejalad '(pukk)jalgadega alusraam jt'}

Udo Uibo (2014: 934-935) on osutanud, et liitsõna (k)raejalad, (k)raepuud S Lä Ha PõPä PõV1 M '(pukk)jalgadega alusraam lauaplaadi, leivaküna jne toeks; pukkidel magamisraam; kanderaam (nt surnuraam; kivikandmisraam ehitusel); niiepakk', ,tänapäeva vaatevinklist hämara esiosaga $(k)$ rae aluseks on alamsaksa sõna schrage '(põik)alus (kahe paari ristatud jalgadega, nt saagimispukk, tünnialus jne), eriti laudadel ja pinkidel, ka 
kaubalett)'. [---] Tänapäeva saksa keeles vastab sellele sõna Schragen 'telling, alus; pukk[-jalg]; saagimispukk'“. Uibo etümoloogia usutavust kinnitab alamsaksa rööplaen läti keeles skrãgis, mrd krãgis 'lauaplaadi, leivaküna alusraam, saepukk; magamisraam; õmblusraam; järi, jalapink jt' (ME 2: 265; ME 3: 889; EH 2: 508); läti keele vahendusel on alamsaksa sõna laenatud kuraliivisse kujul kròi $G$ 'pukkalus; krae' (Suhonen 1973: 140).

Ent (k)rae-kõrval esineb eesti vanemas leksikograafias ka rahe: koolja krae od. rahhe die Todtenbahre [surnuraam, puusärgi alus] d. (Hupel 1780: 189; 1818: 97), rahhe (koolja rahhe) Todtenbahre d. (ibid.: 253). Hupeli järgi on selle esitanud Wiedemann (1973: 918): kōl'ja-r[ahe] (Hup.) Todtenbahre, $=k\left[\bar{o} l^{\prime} j a\right]-r \bar{a} m$, samas allikas lisaks veel samatähenduslik rahe-jalg $=r \bar{a} e-j[a l g], k r a \bar{e}-j[$ alg] (ibid.: 918). Rahe laenualus ei saa olla ülaltoodud asks schrage, sest eesti keele alamsaksa laenudes on sõnasisese - $g$ - substituut poolheliline meediaklusiil $-G^{-}$, teatud tingimustel ka $-j-$, kuid mitte $-h$ - (vt detailsemalt Liin 1968: 85, 89-90). Julius Mägiste (EEW VIII: 2382) arvates kuuluvad (k)rae- ja rahe(-) etümoloogiliselt kokku ja $k$-variandis krae- on seletatav rahvaetümoloogiaga, mis on sidunud $r a(h) e$ sõnadega krae, kraag 'krae'. Edasi on Mägiste oletanud, et eesti esinemus on võib-olla seotud läänemeresoome rahi-perega. Alamsaksa laenu põimumine ja liitumine häälikuliselt, aga ka mõisteliselt lähedase rahe-sõnaga ning selle endasse sulandamine on ülimalt tõenäoline, pidades silmas sedagi, et eesti keel tunneb juhte, kus $h$ on võinud lühikeste vokaalide vahelt kaduda (Kask 1967: 99).

Läänemeresoome rahi-peresse kuuluvad lvK ra'i $\left(<*_{\text {raji }}<*_{\text {rahi }}\right)$ 'tool', ke `ykšep̌pà $r$. 'kingsepatool', mo 'tškin' $r$. 'tool, millel tambiti kartuliputru', oựkkâks $r$. 'auguga tool', vitsà r. 'vitsapainik [riist tünni-, rattavitste koolutamiseks]' (Kettunen 1938: 328ab; Viitso, Ernštreits 2012: 263), sm mrd rahi : rahin 'seljatoeta (tav lühike) pink; järi, taburet; ahjupink; ahjukuru; saunalava; magamislavats; piimapukk; kahele teineteise järel olevale reele pandav raam', vasikka pantiin $r[$ ahi $]$ in 'vasikas pandi pingi (? puki) peale, s.o tapeti', reikärahi 'aukjäri, s.o auguga tool (väikelapse seisu-, käimistool)', rahitsa $(<$ rahi + lavitsa) 'lavits, pink' (NyS 2: 615; Vuorela 1979: 375; SKES III: 712; SSA 3: 37), is rahi : rahin, rähi : rähi- 'pink, lavits; rabamispink (rukkivihkude rabamiseks kasutatud pingikujuline laud, mille üks ots oli vastu maad, teise otsa all kaks jalga', ütturahi 'auguga tool (mille all oli ööpott)' 
(Nirvi 1971: 462, 496, 628); Hevaha rahi: ruiz meil särettii rahhiin 'rukis meil rabati vastu pinki' (Laanest 1997: 163), krjV rl rahi : rahin 'pink' (Jussila 2009: 316).

SKES (III: 712) kirjeldab rahi läänemeresoome sõnana, mis levib soome, karjala ja liivi keeles, SSA (3: 37) on lisanud isuri esinemuse, kuid kumbki allikas ei nimeta eesti vastet, ehkki rahe etümoloogiline siiakuulumine on ilmne. Osmo Nikkilä (1998: 93) on oletanud, et rahi ja rah-na, -no, -nu 'lõmmust peergude kiskumiseks raiutud tükk; põllurull', eesti rah-n 'suur puupakk; suur kivikamakas' on samatüvelised, esindades sufiksivaheldusjuhtu $-n V$ : $-\varnothing$. Pole välistatud, et rahn jt on laen samatüvelisest balti laenualusest, mille jätkajaks on ld krašnià 'kivihunnik põllul, raun, kuhi, virn' ja mitte blt *ransta-: ld rãstas 'palk, puupakk', nagu on kahtlemisi oletanud Jalo Kalima (1936: 149).

Oletan, et rahi on balti laen, millele olen tähelepanu juhtinud juba varemgi (Vaba 2011: 754), kuid detailse etümoloogilise arutluse esitan käesolevas artiklis. Läänemeresoome rahi oletatav balti (resp. baltoslaavi?) laenualus on *krasia-. Tänapäeva balti keelte vasteid iseloomustab vahelduv vokalism ja morfoloogilise struktuuri mitmekesisus: ld krãse 'tool, leentool; taburet; madal jalapink; istekoht' (> vlgvn van крося 'tool', vt Laučiūtè 1982: 96; Zinkevičius 1987: 129), krasià 'seljatoega sohvataoline puupink; (leen)tool; väikelapse seisu-, käimistool; järi, väike pink, jalapink', krasẽle dem 'järi, madal pingike, jalapink; taburet', kràstis (krãsiasi, krãsési) $=$ séstis $i$ krasę 'istuma toolile ja naalduma seljatoele', vrd ka sekundaarvariante ld krẽsè, kresẽe, krèsẽle dem '(leen)tool' (> pl van kresć id., vt Laučiūtė 1982: 96), kresià '(leen)tool; sohva', lt kreša 'väike pink' (lt > lvK kreš'š', mitm kreš'šs' '̀ 'järg, jalapink / schemel = pi 'ški ra'i', vt Kettunen 1938: 153b). Samatüvelised tuletised on nt ld kréslas 'tool, seljatoega tool, pink', krẽstas 'lavats, seljatoega istepink' (> vlgv крэ́сла 'püksitagumik (püksiharude vahele õmmeldud rombikujuline vahetükk); iste', vt Laučiūtẻ 1982: 144), lt krệsls 'tool, voki jalgpuu, puurest' (> lvS kräsl jt 'tool', vt Kettunen 1938: 153b), mpr creslan 'leentool'. Balti tüvel on usutavaid etümoloogilisi vasteid üksnes ida- ja lääneslaavi keeltes, sh nt vn кре́слó 'tugitool, leentool, ree seljatugi' ( $>$ eesti kresla jt 'ree varvuline seljatugi; seljatoega sõiduregi; ree laiendusraam; tugitool', vt Must 2000: 138-139), pl krzesto '(seljatoega) tool' jt (ME I: 274, 276; Pokorny 2: 617-618 sub *kred- 'talastik'; Būga 1959: 162-163, 165; LEW I: 294; Toporov 1984: 179-183; Sabaliauskas 1990: 126-127; LEV 
I: 424; Smoczyński 2016: 599; ALEW 1: 519; http://www.lkz.lt; ÈSSJa 12: 126-129 sub *kreslo $\sim$ *krěslo).

Analoogiline substitutsioonijuhtum, s.o $\operatorname{lms} h<$ blt $*_{s}$, on nt eesti lahja, mrd lahi, laih, sm laiha jt $<$ hlms *laiha $<$ vlms *lajša $<$ blt *laisa-. Vytautas Mažiulise (1993: 268-270) järgi on blt *kras- *kres- tähendusväljas võimalik esile tuua mitu semantilist liini, sh 'kokku liitma, ühendama, tugevdama', 'punuma, punutis' ja 'istuma'. Olgu siinkohal lisatud, et iste kuulus muinasleedulaste oluliste hauapanuste hulka (Vèlius 1996: 576).

Läänemeresoome rahi tuumtähendus on 'järi, s.o iste, millel polnud seljatuge ja tõenäoliselt ka jalgu', vrd Haljala rahvalaulu (1912, VK: 609): istun alvale järille, / järille jalatumale. Tänapäevane tool ilmus Baltikumis talupoja elamusse alles XVIII saj, kuid veel XIX saj I poolel leidus toole Eesti taludes vähe, needki peamiselt piduliku istmena ja kingitusesemena. Tegemist oli nii Eestis kui ka naabermaades tavaliste raamtoolidega, mille neli jalga olid omavahel ühendatud pulkadega (raamiga) (Võti 1978: 103-120; ERL 1995: 47, 287). Kaugemast minevikust on teada, et Eestis kinnitati pingid ja magamisasemed rehetoa seinte külge. XIX saj II poolel seisid nt Muhu rehetoa pingid juba neljal jalal ja söögilaua otsas olid vajaduse korral väikesed kolme või nelja jalaga pingid ehk raejalad (Rullingo 2001: 427).

Läänemeresoome keelte põhjarühma rahi on $i$-tüvi, kuid eesti rahe on kohanenud $e$-tüveliste noomenitega. Teadaolevatest baltismidest esindavad $i$-tüvelisi nt kurt: kurdi (< blt *kurtia-), sm keli 'tee-olud, suusalumi, -rada' (< blt *kelia-), eesti mrd lauk: laugi 'valge vööt looma otsmikul', sm laukki : laukin id. (< hlms *laukkoi). Pole välistatud, et kõik need juhtumid esindavad vanu $i$-liitelisi deminutiivtuletisi (vt ka Nieminen 1944: 249-250).

\section{Rikkuma 'katki tegema jt'}

Kõne all on ulatusliku derivatiivse ja semantilise hargmikuga läänemeresoome sõnapere *rikkoi- (< vlms *rikka-, vt EEW VIII: 2488): eesti rikkuma, mrd ka rikkima : rikib, rikma 'katki tegema, ära lõhkuma, kõlbmatuks muutma, kahjustama, purustama, hävitama; kellelegi halba mõju avaldama; kehtivast üle astuma; riknema; van maha lõhkuma, laastama; mrd riknema'; Wiedemannil (1973: 955-956) rikkuma, rikkima, rikma 'kahjustama, ära nõiduma; riknema, raisku minema', rōzi rikkuma 
'roosihaigust ohutama', ära rikkuma 'hukutama, laostama, ruineerima, vägistama'. Eesti vanemas leksikograafias leidub rikkuma kohta mh järgmisi teateid: Müller 1600-1606 rickma, rickuda; Rossihnius 1632 rickma; Stahl 1637: 50, 123 verderben / rickma / errarickma, Ehebrechen / abbiello rickma / errarickma; Göseken 1660: 147 brechen (den bund) üllestama / errarickuma, 165 Ehebrechen / Abbi ello rickuma, 200 Gar aus machen / kooldes rickuma / otza pehle teggema, 293 ausmergeln / errarickuma, 399 stören / (zerstören) errarickuda, 424 verderben / (corrumpere) errarickuma, 425 verfälschen / petma / errarickuma, 428 verletzen / (violare) errarickuma, 432 versehren / (verderben) errarickuma; lvK ri kkõ : riǩkù 'rikkuda, vigastada, kõlbmatuks muuta, kahjustada; rüvetada', rǐkkàbõ 'katki minna; raisku, halvaks minna, rikneda' (Kettunen 1938: 337ab; Viitso, Ernštreits 2012: 268); vdj rikkoa, rikkua : rikon 'lõhkuda, purustada, katki teha, katki lüüa; rikkuda; kõlbmatuks muuta, kahjustada; neitsilikkust röövida; nõiduda', rikkauta 'katki minna, puruneda', rikki 'katki, lõhki; katkine' (VKS 5: 67-69); sm rikkoa : rikon 'katki teha, purustada, ära lõhkuda, lõhki rebida, katki kiskuda; lammutada; puruks litsuda; katkestada, lõpetada; kahjustada, hävitada; (käsku) rikkuda, üle astuda; nõidusega kahjustada', rikkua = rikkoutua intr, mrd rikata 'katki minna, puruneda, rebeneda, laguneda' (NyS 2: 723-724; SKES III: 797-798; SSA 3: 78); is rikkoa 'lõhkuda, purustada, katki teha; kõlbmatuks muuta, kahjustada', rikkoaG 'lõhkuda' (Nirvi 1971: 478; Laanest 1997: 168); krj rikkuo, r'ikkuo 'katki teha, lõhkuda, purustada, kõlbmatuks muuta; kahjustada, vigastada; üle astuda (nt keelust), eksida, sõna, lubadust murda; halvaks minna lasta (nt võil, piimal); neitsilikkust röövida, vägistada; kaetada, nõidusega kahjustada; tappa, surmata', rikkautuo, rikkavuo 'katki minna, puruneda' (http://kaino.kotus.fi/cgi-bin/kks/karjala); lü rikkoda, r'ikkoda, rikta 'surmata, tappa; kõlbmatuks muuta, kahjustada, vigastada', rikkavuda 'rikneda, halvaks minna' (Kujola 1944: 356); vps r'ikta : r'ikob 'tappa, maha, surnuks lüüa, veristada (siga)' (Zajceva, Mullonen 1972: 472).

Läänemeresoome keeltes (v.a lv) on esindatud rikkuma-verbist tuletatud verbaalnoomen ja selle leksikaliseerunud käändevorme, nt eesti mrd rikk: riku riki 'hukk, häving': rikku rikki 'korrast ära, mitte (korralikult) töötavaks; nässu, untsu, hukka; riknenuks', rikkus rikkis 'korrast ära; mitte (korralikult) töötav; nässus, untsus, hukas; riknenud'; rike : rikke 'viga, defekt, korrast ära olek'; vdj rikko: lainõrikko 'lainemurdja, muul', rikki 'katki, lõhki'; sm rikki 'katki, puru; puruks, lõhki; rikkis', 
rikko: kelirikko 'teelagunemine, kehvad teeolud', haaksirikko 'laevahukk, laevaõnnetus'; rike : rikkeen 'üleastumine; väärsamm, eksisamm; viga; eksimus'; is rikki 'katki, lõhki'; krj rikkoh = rikki 'katki, puruks, tükkideks; rikutud, nässus'; lü rikond '(nõia tekitatud) kahju' (SKES III: 797-798; EEW VIII: 2488-2489; SSA 3: 78). Kaugemates soome-ugri keeltes selle verbitüve kohta teated puuduvad.

Kõnealusele läänemeresoome verbile on esitatud germaani etümoloogia. Germaani päritolu oletus pärineb soome folkloristilt ja leksikograafilt Christfrid Gananderilt, kes 1787 kõrvutas seda gooti verbiga brikan '(katki) murdma, purustama'. Hiljem on püütud germaani etümoloogiat üksikasjalikult välja arendada ja põhjendada: germ *brekan-, vrd vingl brecan 'katki murdma', kasks breken id., vüsks brehhan id. (vt täpsemalt LäGloS 3: 156-157, seal ka asjaomane kirjandus; vrd veel Pokorny 1: 165 sub *bhreg- '(katki) murdma'). Kuid läänemeresoome keelte etümoloogiasõnaraamatud kas tõrjuvad või ei nimeta rikkuma-verbi germaani etümoloogiat (vt SKES III: 797-798; EEW VIII: 2488-2489; Raun 1982: 143; SSA 3: 78; Häkkinen 2004: 1050). Ka läänemeresoome keelte germaani laene käsitlevad monograafiad (Karsten 1943; Hofstra 1985) ei käsitle rikkuma-juhtumit. SKES-is on esitatud oletus (vt ka Hakulinen 1968: 244), et rikkoa jt on seotud sõnaperega rikka : rikan 'puru, praht', millele võiksid osutada piirijuhtumid, nagu sm mrd rikkoa 'puhastada prahist marju', rikkeet 'tulehakatis, laastud'. Seegi etümologiseerimiskatse pole leidnud heakskiitu ja omasõnavaras on raske leida keeleainest, millega rikkuma etümoloogiliselt usutavalt haakuks.

Juba eespool nimetatud Leedu keeleuurija Kazimieras Jaunius on u 1879-1890 paiku kõrvutanud soome sõnu rikki 'katki' ja rikon : rikkoa 'katki teha, lõhki kiskuda; rikkuda (lubadust)' leedu verbiga rikinti 'segama, tülitama, häirima; vilja peksma (vartadega)' ja u 1880-1890 eesti sõnu rike : rikke, rikkuma : rikun leedu verbiga -rikti 'eksima; lagunema, purunema' (Jaunius 1972: 278, 341).

Alljärgnevas kaalun selle tähelepanuta jäänud embrüonaalse etümologiseerimiskatse usutavust. Võimalik balti laenualus on *rika-, mille jätkajad on ld rikti (riñka reñka rinksta, riko) 'koost lagunema, katki minema, purunema; eksima, segi ajama, viga tegema, ebaõigesti, ebatäpselt tegema (nt rääkides, loendades), vääratama', aprikti 'segamini, segi, sassi ajama; eksima, midagi valesti, vigaselt tegema', apsirikti refl 'eksima, viga tegema, vääratama, valesti (kokku) arvutama', parikti 'eksima, viga 
tegema; eksima (teelt); koost lagunema, purunema; otsa saama, lõppema', surikti 'eksima, viga tegema, vääratama; segi, sassi minema; ära, koost lagunema, korrast ära, rikki minema', rikdýti'eksima; eksitama, eksiteele viima; häirima, segama, takistama, tüliks ees olema; lõhkuma, rikkuma', rik(d)inti 'häirima, segama; segi ajama, ära rikkuma', rik(l)us 'ebajärjekindel, ebaühtlane, katkendlik': $r$. dárbas 'aeglaselt edenev, laabuv töö, s.o töö, mille juures kergesti võib eksida ja mis seetõttu edeneb aeglaselt', rikée, rike 'viga, eksitus, vääratus (nt kangaviga)'; vrd ka rikti 'jultuma, kõlvatuks muutuma, raisku minema, alla käima; vihaseks saama' (www. lkz.lt); rikti on etümoloogiliselt seotud sõnaperega riẽkti, raikýti '(lahti) lõikama' ja põhitähendus Ernst Fraenkeli järgi 'koost lagunema, katki minema' (LEW II: 734-735; Smoczyński 2016: 1097-1098).

Ent läänemeresoome sõnapere lähtena tuleb silmas pidada teistki balti etümoni *trika-, mille jätkajaid on ld trikti (triñka, triko) 'eksima, viga tegema, vääratama, sassi minema, takerduma (kõnes, loendades jne), kogelema; koost lagunema; laostuma; korrast ära, rikki, katki minema (nt tervis); enneaegu sünnitama; hulluks, pööraseks, omadega segi minema, aru kaotama, märatsema; marutaudi haigestuma (koer); vihaseks saama; segadusse sattuma, hämmelduma, kohmetuma; vallatust tegema, veidralt, ebaviisakalt käituma; häirima, segama, tülitama', ịtrikti 'midagi innukalt tegema hakkama; vihaseks saama, raevuma', ištrikti 'koost, ära lagunema, katki, räbalateks kuluma, narmendama, üles, õmblustest hargnema; enneaegu sünnitama, nurisünnitama; marutaudi haigestuma, hulluks minema (koer)', patrikti 'kõnes, lugemisel takerduma, kogelema, toppama jääma; eksima, viga tegema (tav loendades, arvutades); nurjuma, luhtuma; nurisünnitama, enneaegu sünnitama; segadusse sattuma, kohmetuma; rahutust tundma hakkama; märatsema; segaseks, arust ära minema; hulluks minema (koer); raevuma; vallatust, koerust tegema', patrikęs: p. šuõ 'marutõbine koer', sutrikti 'korrast ära, rikki minema, segamini minema; eksima, viga tegema (nt arvutuses), vääratama; takerduma (kõnes, lugemisel), kogelema, toppama jääma; korrast ära, katki, rikki minema; nurjuma; segadusse sattuma, kohmetuma, hämmelduma', pértrikti 'tulivihaseks saama', užtrikti 'maruvihaseks saama', trikdýti 'rikkuma (rahu), häirima, segama, tülitama; takistama; segamini, korrast ära ajama; sassi, segi, segamini minema, takerduma; segadusse sattuma, kohmetuma, hämmelduma'. Sõnaperega on ablautsuhtes ld trãkas 'hull, märatsev', 1t traks 'taltsutamatu; hull, meeletu, marutõbine', ld trẽkti (trẽkia, trẽkè) 
'(ära) rikkuma, vigastama, kahju tegema; tapma, veristama (kodulooma); raiskama, pillama; ära määrima, reostama; mustama, laimama' (www.lkz. 1t; Būga 1959: 465; LEW II: 1116, 1122-1123; Smoczyński 2016: 1504; ALEW 2: 1124). Vene etümoloog Ljubov Kurkina on osutanud, et leedu sõnaperel on võimalikke vasteid slaavi keeltes: sl *tъrk-, *stъrk-, vrd vn то́ркать 'lükkama, tõukama, peksma, kolkima, lõhkuma' jt, slvn mrd otrknjen: otrknjen krompir 'riknenud kartul', trknjen 'kõrbenud; hull, peast segane', utŕkniti 'üle minema, kaduma, lakkama (valu)', trackáti 'välja, laiali puistama, ära kulutama, raiskama' (Kurkina 1976: 45-47).

Häälikuliselt on germaani ja balti laenualused võrdväärselt arvestatavad, kuid semantiliselt on balti laenuoletus usutavam. Mõlema proponeeritud balti laenualuse jätkajad koos tuletistega on erakordselt suure semantilise mahuga: nii balti kui ka läänemeresoome sõnaperede tuumtähendus on 'tekitama ainelist kahju (s.o katki tegema, lõhkuma)', millest (tõenäoliselt teineteisest sõltumatult) on hargnenud muud semantilised liinid.

\section{Lühendid $^{1}$}

gt - gooti keel; hlms - hilisläänemeresoome algkeel; krjV - vienakarjala keel; lvK - kuraliivi keel; lvS - salatsiliivi keel; lü - lüüdi keel; mpr - muinaspreisi keel; mrd - murdesõna; $\mathrm{pl}$ - poola keel; $\mathrm{rl}$ - rahvaluulekeel; slvn - sloveeni keel; vingl - vanainglise keel; vlms - varaläänemeresoome algkeel

\section{Kirjandus}

ALEW = Altlitauisches etymologisches Wörterbuch. 1-3, 2015. Unter der Leitung von Wolfgang Hock und der Mitarbeit von Elvira-Julia Bukevičiūtè und Christiane Schiller; bearbeitet von Rainer Fecht, Anna Helene Feulner, Eugen Hill und Dagmar S. Wodtko. (= Studien zur historisch-vergleichenden Sprachwissenschaft 7. Hrsg. Harald Bichlmeier und Velizar Sadovski.) Hamburg: Baar.

Anderson, Nicolai 1879. Studien zur Vergleichung der indogermanischen und finnisch-ugrischen Sprachen. (= Verhandlungen der Gelehrten Estnischen Gesellschaft zu Dorpat 9.) Dorpat.

Ariste, Paul 1933. Eesti-rootsi laensõnad eesti keeles. (=Acta et Commentationes Universitatis Tartuensis (Dorpatensis) B XXIX, 3.) Tartu.

${ }^{1}$ Esitatud on üksnes need lühendid, mida aastaraamatu lühendinimestikus pole. 
Blažek, Václav 1998. Old prussian birds names. - Colloquium Pruthenicum Secundum. Ed. Wojciech Smoszyński. Kraków: Universitas, 7-23.

Būga, Kazimieras 1959. Rinktiniai raštai II. Vilnius: Valstybinè politinès ir mokslinès literatūros leidykla.

EEW = Julius Mägiste. Estnisches etymologisches Wörterbuch. I-XII, 2000. Helsinki: Finnisch-Ugrische Gesellschaft.

EH = Jānis Endzelīns, Edīte Hauzenberga. Papildinājumi un labojumi K. Mülenbacha Latviešu valodas vārdnīcai. I-II, 1934-1946. Rīgā: Grāmatu apgāds.

EKMS = Andrus Saareste. Eesti keele mõisteline sõnaraamat. I-IV, 1958-1963. Dictionnaire analogique de la langue estonienne. Avec un index pourvu des traductions en français. (= Eesti Teadusliku Seltsi Rootsis väljaanne nr. 3.) Stockholm: Vaba Eesti.

EMS = Eesti murrete sõnaraamat. I-VI, 1994-2017. Eesti Teaduste Akadeemia Eesti Keele Instituut. Tallinn: Eesti Keele Instituut, Eesti Keele Sihtasutus.

ERL $=$ Eesti rahvakultuuri leksikon. 1995. Koost. ja toim. Ants Viires. Tallinn: Eesti Entsüklopeediakirjastus.

ÈSSJa 1- = Этимологический словарь славянских языков. Праславянский лексический фонд. 1-, 1974-. Отв. ред. О. Н. Трубачев. Москва: Наука. http://etymolog.ruslang.ru.

Göseken, Heinrich 1660. Manuductio ad Linguam Oesthonicam, Anführung Zur Öhstnischen Sprache, Bestehend nicht alleine in etlichen præceptis und observationibus, Sondern auch In Verdolmetschung vieler Teutschen Wörter. Reval: Adolph Simon.

Hakulinen, Lauri 1968. Suomen kielen rakenne ja kehitys. Kolmas, korjattu ja lisätty painos. Helsinki: Otava.

Hofstra, Tette 1985. Ostseefinnisch und Germanisch. Frühe Lehnbeziehungen im nördlichen Ostseeraum im Lichte der Forschung seit 1961. Groningen: Drukkerij Van Denderen B.V.

Hupel, August Wilhelm 1780. Ehstnische Sprachlehre fuer beide Hauptdialekte, den revalschen und doerptschen; nebst einem vollstaendigen Woerterbuch. Riga, Leipzig: Johann Friedrich Hartknoch.

Hupel, August Wilhelm 1818. Ehstnische Sprachlehre für die beyden Hauptdialekte, den revalschen und dörptschen, nebst einem vollständigen ehstnischen Wörterbuche. Zweyte durchgängig verbesserte und vermehrte Auflage. Mitau: J. F. Steffenhagen und Sohn.

Häkkinen, Kaisa 2004. Nykysuomen etymologinen sanakirja. Juva: WSOY.

Jaunius, Kazimieras 1972. Kalbininko Kazimiero Jauniaus rankraštinis palikimas. Katalogas ir publikacijos. Рукописное наследие языковеда Казимераса Яунюса. Каталог и публикации. Parenge S. Skrodenis. 
Spec. redaktorius A. Lukošiūnas. Vilnius: Lietuvos TSR valstybinè respublikinè biblioteka.

Jussila, Raimo 2009. Kalevalan sanakirja. Helsingissä: Kustannusosakeyhtiö Otava. Kalima, Jalo 1936. Itämerensuomalaisten kielten balttilaiset lainasanat. (= Suomalaisen Kirjallisuuden Seuran toimituksia 202.) Helsinki: Suomalaisen Kirjallisuuden Seura.

Karaliūnas 1997 = С[имас] Каралюнас. Из наблюдений над балто-славянской лексикой (балт. * k kurti\}, слав. * \{kuriti\}). - Балто-славянские исследования 1988-1996. Сборник статей. Москва: Наука, 259-275.

Karsten, Torsten Evert 1943. Finnar och germaner. Folk- och kulturberöringar från tre årtusenden. (= Folkmålsstudier IX-X.) Helsingfors.

Kask, Arnold 1967. Eesti keele ajalooline grammatika I. Häälikulugu. Tartu: Tartu Riiklik Ülikool, eesti keele kateeder.

Kettunen, Lauri 1938. Livisches Wörterbuch mit grammatischer Einleitung. (= Lexica Societatis Fenno-Ugricae V.) Helsinki: Suomalais-Ugrilainen Seura.

Kujola, Juho 1944. Lyydiläismurteiden sanakirja. Ainekset keränneet K. Donner, J. Kalima, L. Kettunen, J. Kujola, H. Ojansuu, E. Pakarinen, Y. H. Toivonen, E. A. Tunkelo. Toimittanut ja julkaissut J. Kujola. (= Lexica Societatis Fenno-Ugricae IX.) Helsinki: Suomalais-Ugrilainen Seura.

Kurkina 1976 = Л[юбовь] В[икторовна] Куркина. Этимологические заметки. - Этимология 1974. Москва: Наука, 44-59.

Laanest, Arvo 1997. Isuri keele Hevaha murde sõnastik. Ainestiku kogunud ja käsikirja koostanud Arvo Laanest. Tallinn: Eesti Keele Instituut.

Laučiūtė 1982 = Юрате Алоизовна Лаучюте. Словарь балтизмов в славянских языках. Ленинград: Наука.

LEV = Konstantīns Karulis 1992. Latviešu etimologijas vārdnīca. I-II. Rīga: Avots. LEW = Ernst Fraenkel. Litauisches etymologisches Wörterbuch. I-II, 1962-1965. Heidelberg: Carl Winter, Universitätsverlag, Göttingen: Vandenhoeck \& Ruprecht.

Liin, H[elga] 1968. Alamsaksa laensõnad 16. ja 17. sajandi eesti kirjakeeles. Väitekiri filoloogiakandidaadi teadusliku kraadi taotlemiseks. Tartu: Tartu Riiklik Ülikool. [Käsikiri.]

Lõo, J[aan] 1913. Meie koduloomade nimetused 2. - Eesti Kirjandus 7, 257-262.

LäGloS = Andries Dirk Kylstra, Sirkka-Liisa Hahmo, Tette Hofstra, Osmo Nikkilä. Lexikon der älteren germanischen Lehnwörter in den ostseefinnischen Sprachen. I-III, 1991-2012. Amsterdam-Atlanta: Rodopi.

Mažiulis, Vytautas 1993. Prūsų kalbos etimologinis žodynas. 2. Vilnius: Mokslo ir enciklopedijų leidykla.

Mažiulis, Vytautas 1996. Prūsų kalbos etimologinis žodynas. 3. Vilnius: Mokslo ir enciklopedijų leidykla. 
ME = K. Mīlenbacha Latviešu valodas vārdnīca. 1-4, 1923-1932. Rediǵējis, papildinājis, turpinājis J. Endzelīns. Rīgā: Herausgegeben vom lettischen Bildungsministerium / Herausgegeben vom lettischen Kulturfonds.

Must, Mari 2000. Vene laensõnad eesti murretes. [Toim. Lembit Vaba.] Tallinn: Eesti Keele Sihtasutus.

Mäger, Mart 1967. Eesti linnunimetused. Eesti NSV Teaduste Akadeemia Keele ja Kirjanduse Instituut. Tallinn: Eesti NSV Teaduste Akadeemia.

Müller 1600-1606 = Külli Habicht, Valve-Liivi Kingisepp, Urve Pirso, Külli Prillop 2000. Georg Mülleri jutluste sõnastik. Toim. Jaak Peebo. (= Tartu Ülikooli eesti keele õppetooli toimetised 12.) Tartu: Tartu Ülikool.

Nieminen, Eino 1944. Eräistä balttilaisista lainasanoistamme ja niiden vastineista. Virittäjä 48, 238-250.

Nikkilä, Osmo 1998. nop-ea $\rightarrow$ nop-sa, sel-keä $\rightarrow$ sel-vä: suffiksinvaihto ja suomen sanojen etymologiointi. - Kirjoituksia muoto- ja merkitysopista. Toim. Urho Määttä, Klaus Laalo. (= Folia Fennistica \& Linguistica 21.) Tampere: Tampereen yliopiston suomen kielen ja yleisen kielitieteen laitos, 77-101.

Nirvi, R. E. 1971. Inkeroismurteiden sanakirja. (= Lexica Societatis FennoUgricae XVIII.) Helsinki: Suomalais-Ugrilainen Seura.

NyS = Nykysuomen sanakirja. Lyhentämätön kansanpainos. 1-3, 1978. Kuudes painos. Päätoim. Matti Sadeniemi. Porvoo-Helsinki-Juva: Werner Söderström Osakeyhtiö.

Pokorny $=$ Julius Pokorny. Indogermanisches etymologisches Wörterbuch. 1-2, 1949-1959. Bern: A. Francke AG Verlag.

Raun, Alo 1982. Eesti keele etümoloogiline teatmik. Rooma-Toronto: Maarjamaa.

Rossihnius 1632 = Valve-Liivi Kingisepp, Külli Habicht, Külli Prillop 2002. Joachim Rossihniuse kirikumanuaalide leksika. (= Tartu Ülikooli eesti keele õppetooli toimetised 22.) Tartu: Tartu Ülikool.

Rullingo, Ago 2001. Muhumaa. Loodus aeg inimene. Tallinn: Eesti Entsüklopeediakirjastus.

Ränk, Arvi 1995. Eesti etnograafia sõnaraamat. Tallinn: [Ränk].

Ränk, Gustav 1939. Saaremaa taluehitised. Etnograafiline uurimus I. Ehitiste üksikosad, elamu ja kõrvalhooned, mis osalt täidavad elamu ülesandeid. (= Õpetatud Eesti Seltsi Kirjad V.) Tartu: Õpetatud Eesti Selts.

Saareste, Albert 1924. Leksikaalseist vahekordadest eesti murretes I. Analüüs 60 kaardi ja 1 skeemiga. (= Acta et Commentationes Universitatis Dorpatensis $\mathrm{B} \mathrm{VI}_{1}$.) Tartu: Kirjastus-Ühisuse „Postimehe“ trükk.

Sabaliauskas, Algirdas 1990. Lietuvių kalbos leksika. Vilnius: Moksla.

Sereiskis, B[enjaminas] 1933. Lietuviškai-rusiškas žodynas. Kaunas: Med. d-ro A. Lapino ir Grigorijaus Volfo leidinys. 
SKES $=$ Yrjö H. Toivonen, Erkki Itkonen, Aulis J. Joki, Reino Peltola. Suomen kielen etymologinen sanakirja. I-VII, 1955-1981. (= Lexica Societatis Fenno-Ugricae XII, 1-7. Tutkimuslaitos „Suomen Suvun“ julkaisuja III. / Kotimaisten kielten tutkimuskeskuksen julkaisuja 2.) Helsinki: Suomalais-Ugrilainen Seura.

Smoczyński, Wojciech 2016. Słownik etymologiczny języka litewskiego. Wydanie drugie, poprawione i znacznie rozszerzone. Na prawach rękopisu. https://dl.dropboxusercontent.com/u/21280621/Smoczyński W. Słownik etymologiczny języka litewskiego.pdf.

SSA = Suomen sanojen alkuperä. Etymologinen sanakirja. 1-3, 1992-2000. Päätoim. Erkki Itkonen, Ulla-Maija Kulonen. (= Suomalaisen Kirjallisuuden Seuran toimituksia 556. Kotimaisten kielten tutkimuskeskuksen julkaisuja 62.) Helsinki: Suomalaisen Kirjallisuuden Seura, Kotimaisten kielten tutkimuskeskus.

Stahl, Heinrich 1637. Anführung zu der Estnischen Sprach, auff Wolgemeinten Rath vnd Bittliches Ersuchen, publiciret von M. Henrico Stahlen. Revall: Chr. Reusner.

Suhonen, Seppo 1973. Die jungen lettischen Lehnwörter im Livischen. (= Suomalais-Ugrilaisen Seuran toimituksia 154.) Helsinki: SuomalaisUgrilainen Seura.

Zajceva, Mullonen 1972 = Мария Ивановна Зайцева, Мария Ивановна Муллонен. Словарь вепсского языка. Ленинград: Наука.

Zinkevičius, Zigmas 1987. Lietuvių kalbos istorija. II. Iki pirmujų raštų. Vilnius: Mokslas.

Tihase, Karl 1974. Eesti talurahvaarhitektuur. Tallinn: Kunst.

Toivonen, Y. H. 1928. Zur geschichte der finnisch-ugrischen inlautenden affrikaten. (= Finnisch-Ugrische Forschungen XIX.) Helsinki.

Tooms, Mikk 1933. Mõni juhtum $\delta>l$ eKirdes. - Eesti Keel 1, 5-10.

Toporov 1984 = В[ладимир] Н[иколаевич] Топоров. Прусский язык. Словарь K-L. Отв. ред. Вяч. Вс. Иванов. Москва: Наука.

Uibo, Udo 2014. Etümoloogilised märkmed (XV). - Keel ja Kirjandus 12, 933-938.

Vaba, Lembit 1997. Uurimusi läti-eesti keelesuhetest. Tallinn-Tampere: Eesti Keele Instituut, Tampereen yliopiston suomen kielen ja yleisen kielitieteen laitos.

Vaba, Lembit 2011. Balti laenude uurimine avab meie kauget minevikku. - Keel ja Kirjandus 10, 734-763.

Vèlius, Norbertas 1996. Baltų religijos ir mitologijos šaltiniai. 1. t. Nuo seniausių laikų iki XV amžiaus pabaigos. Vilnius: Mokslo ir enciklopedijų leidybos institutas.

Viitso, Tiit-Rein, Valts Ernštreits 2012. Līvõkīel-ēstikīel-leţkīel sõnārōntõz. Tartu, Rīga: Tartu Ülikool, Latviešu valodas aǵentūra. 
VK $=$ Haljala regilaulud. 1, 1989. Toim. E. Laugaste. (= Monumenta Estoniae antiquae I. Vana kannel VI, 1.) Tallinn: Eesti Raamat.

VKS = Vadja keele sõnaraamat. 1-7, 1990-2011. Toim. Elna Adler, Merle Leppik, Silja Grünberg. Tallinn: Eesti Keele Instituut.

Vuorela, Toivo 1979. Kansanperinteen sanakirja. Porvoo-Helsinki-Juva: Werner Söderström Osakeyhtiö.

Võti, Tiina 1978. Eesti talupoja toolid. - Etnograafiamuuseumi aastaraamat XXXI, 103-120.

Walde, Alois 1930. Vergleichendes Wörterbuch der indogermanischen Sprachen I. Herausgegeben und bearbeitet von Julius Pokorny. Berlin, Leipzig: Gruyter \& Co.

Wiedemann, Ferdinand Johann 1973 (1893). Eesti-saksa sõnaraamat. Neljas, muutmata trükk teisest, Jakob Hurda redigeeritud väljaandest. Tallinn: Valgus.

\section{Võrgumaterjalid}

Deutsches Wörterbuch von Jacob und Wilhelm Grimm. 16 Bde. in 32 Teilbänden. Leipzig 1854-1961. Quellenverzeichnis Leipzig 1971. Online-Version vom 28.04.2018. http://woerterbuchnetz.de/cgi-bin/WBNetz/genFOplus. tcl? sigle $=$ DWB\&lemid $=$ GW03854.

Eesti regilaulude andmebaas. http://www.folklore.ee/regilaul/andmebaas.

Jahilinnud. http://www.ejs.ee/wp-content/uploads/2015/02/jahilinnud.pdf.

Karjalan kielen sanakirja. http://kaino.kotus.fi/cgi-bin/kks/karjala.

Lietuvių kalbos žodyno (t. 1-20, 1941-2002) elektroninio varianto I leidimas 2005. http://www.lkz.lt.

Tēzaurs. Skaidrojošā un sinonīmu vārdnīca. www.tezaurs.lv. 


\section{Alternative etymologies IV}

\section{LEMBIT VABA}

The article presents new etymological interpretations of the words kori : korja 'hearth', melek(as) 'stock pigeon', rahe(-): rahejalg, kooljarahe 'bier' and rikkuma 'to spoil, ruin, break, etc'.

Kori : korja 'hearth' is a forgotten word in modern Estonian, which is known from northwestern Läänemaa as well as Hiiumaa. Nikolai Anderson suggested over a hundred years ago that kori belongs together with the Finnish word korju 'bear's (above-ground) winter lair'. Anderson's comparison has been cited by Andrus Saareste as well as, with some hesitation, in Finnish etymological dictionaries. Julius Mägiste did not attempt to explain the word's origin in his Estnisches etymologisches Wörterbuch. Due to both phonetic and semantic considerations, an etymological link between Estonian kori : korja and Finnish korju is impossible. I suggest that kori : korja is a Baltic loan from the word family represented in modern Baltic languages by Lithuanian kùrti (kùria, kúrè) 'to heat up, start a fire etc', ǔžkura(s) 'oven full of wood; widower', užkurỹs 'man who has married a widow and moved into her home; man living in his wife's parents' house'. This Baltic word family has equivalents with fire- and hearth-related meanings in other Indo-European languages, e.g. Old Russian курити 'to start a fire, ignite', Old English here 'fireplace, hearth, small oven' and the stem variant with a final dental consonant heord 'hearth, fireplace, home etc'. Kori : korja presumes a Baltic loan base with the stem ia-, *kuria-, presumed original meaning 'fire, fireplace'.

Melek(as) 'stock pigeon' occurs sporadically in different parts of northern Estonia. This bird name has been seen as onomatopoetically motivated (Andrus Saareste, Mart Mäger, and with hesitation Alo Raun), a view which has been rejected by Julius Mägiste. Another suggestion is that melekas derives from a common Finnic-Mordvin stem, in which - $l$ - may have developed from the affricate * ${ }^{2}$, cf. dialectal Finnish mettinen 'turtle dove', Erzya Mordvin m'eče, m'eča 'dove' (Y. H. Toivonen, Mikk Tooms), but Mägiste is skeptical of this explanation as well, and sees the word as more likely a contamination of mehikas $\sim$ mehekas 'wood dove' + meltsas 'green woodpecker, wood dove'. I argue that the explanation of the origin of the word melek(as) must take into account the observation of the Lithuanian linguist, who in the 1880s-1890s drew a parallel to the Lithuanian bird name meletà 'Picus viridis, Dryocopus martius, Merops apiaster, Coracias garrulus; chatterbox, sweet-talking person'. Baltic *melat $\bar{a} \sim *^{*}$ meletā is etymologically 
related to the Balto-Slavic word family *mel- 'to rub, grind; chatter': Lithuanian málti 'to grind; speak too much, blather, prattle', dialectal Russian мелея́ 'grinder; blabbermouth etc', dialectal Belarusian мэ́лю́x 'Iblabbermouth'. Phonetically, there is no reason not to accept the Baltic etymology. The final syllable *-ta of the Baltic loan base has been replaced by the very productive affix $k(a s)$, which appears in many bird names.

(k)rae- in the compound words $(k)$ raejalad, $(k)$ raepuud 'trestle table, stretcher, barrow' derives from the Low German schrage '(transverse) stand (with two pairs of crossed legs) etc' (Udo Uibo). According to older lexicography, Estonian has known the compound words kooljarahe and rahejalg 'bier, coffin base', which are not related to the aforementioned Low German loan base, because in Low German loans in Estonian, word-internal - $g$ - is replaced by the partially voiced medial stop - $G$-, in some cases also $-j-$, but never $-h$-. Mägiste has presumed that rahe(-) is related to the Finnic word family rahi: Courland Livonian $r a$ ' $i$ 'chair', dialectal Finnish rahi : rahin 'bench with no backboard; stool etc', Ingrian rahi rähi 'bench, stove-bench etc', North Karelian rahi 'bench'. I propose a Baltic etymology for the word rahi: < Baltic *krasia-, cf. Lithuanian krãse 'chair, reclining chair, stool; low footstool; seat', krasià 'sofa-like wooden bench with backboard; (reclining) chair; standing/walking chair for a small child; footrest etc'. This Baltic stem has plausible etymological correspondences only in Eastern and Western Slavic languages, e.g. Russian кре́слó 'armchair, reclining chair, backrest in a sleigh'. An analogous substitution, i.e. Finnic $h<$ Baltic *s, is e.g. Estonian lahja 'lean, thin', dialectal lahi, laih, Finnic laiha etc $<$ Late Proto-Finnic *laiha $<$ Early ProtoFinnnic *lajša $<$ Baltic *laisa-. Estonian rahe 'hail' has conformed to other nouns ending in $e$.

Rikkuma, in dialects also rikkima, rikma to break, ruin, damage, smash, destroy; negatively influence someone; decay, deteriorate; (dialectally) go bad, become spoiled' is a wide-ranging word family found in all Finnic languages: Finnic *rik$k o i-<$ Early Proto-Finnnic *rikka. A Germanic etymology has been proposed for it (Christfrid Ganander 1787), which is rejected by etymological dictionaries of Finnic languages. Another rejected explanation is that of Lauri Hakulinen, who suggested that it is related to the word family rikka : rikan 'dust, scrap, litter'. I propose a Baltic etymology for this Finnic verb stem, deriving from either 1. Baltic *rika-, on the successors of which are Lithuanian rikti (riñka reñka rinksta, riko) 'to disintegrate, break into pieces, be crushed; to be wrong, confuse, err, act wrongly or imprecisely (e.g. when speaking or enumerating), stumble', aprikti 'to confuse, mix up, garble; to be wrong, do something wrong etc' or 2. Baltic *trika-, the successors of which are Lithuanian trikti (triñka, triko) 'to be wrong, make a mistake, stumble, get stuck (when speaking, enumerating, etc), stutter; disintegrate; break, be ruined; to be ruined, go out of order (e.g. health); to prematurely give birth; to go crazy, lose one's mind, rave; to get rabies (of dogs); to get angry; to get 
confused, puzzled; to engage in mischief, act strangely, impolitely; bother, disturb, annoy etc'. Phonetically, the German and Baltic loan bases are equally plausible, but semantically the Baltic explanation is a better fit. The core meaning of both the Baltic and Finnic word families is 'to do material damage (i.e. break, ruin)', from which (likely independently of one another) the other semantic lines have branched off.

Keywords: etymology, loanwords, Estonian language, Finnic languages, Baltic languages, Slavic languages

Lembit Vaba

phorest45@gmail.com 